\title{
Two Types of the Western Pacific Pattern, Their Climate Impacts, and the ENSO Modulations
}

\author{
YING DAI ${ }^{\mathrm{a}}$ AND BENKUI TAN \\ Department of Atmospheric and Oceanic Sciences, School of Physics, Peking University, \\ Beijing, China
}

(Manuscript received 15 September 2017, in final form 20 November 2018)

\begin{abstract}
The western Pacific (WP) pattern is a major teleconnection pattern that influences the wintertime Northern Hemisphere climate variations. Based on daily NCEP-NCAR reanalysis data, this study examines the climate impacts and the El Niño-Southern Oscillation (ENSO) modulation of two types of the WP pattern. The result shows that the WP patterns may arise from precursory disturbances over Asia and the North Pacific or from the Pacific-North American (PNA) pattern of the same polarity as or opposite polarity to that of the WP patterns. Among these WP patterns, the WP patterns that arise from the PNA pattern of the same polarity are most influential on North American near-surface and polar stratospheric air temperatures; furthermore, their frequency of occurrence, amplitude, and duration can be affected by ENSO phases: the positive WP patterns occur more frequently with larger amplitude and longer duration in El Niño than in La Niña; and the negative WP patterns occur less frequently with smaller amplitude and shorter duration in El Niño than in La Niña. The above findings suggest that the PNA pattern plays a crucial role in the climate impacts and the ENSO modulation of the WP patterns.
\end{abstract}

\section{Introduction}

The western Pacific (WP) pattern is one of the major teleconnection patterns over the wintertime Northern Hemisphere (Wallace and Gutzler 1981; Barnston and Livezey 1987). In the lower troposphere, it is characterized by a north-south-oriented dipole centered over Hawaii and Alaska; while in the upper troposphere, it takes the form of a Rossby wave train, with an anomaly centered at the subpolar northern Pacific, and the other two anomalies of opposite sign centered over the subtropical North Pacific and North America (Linkin and Nigam 2008; Orsolini et al. 2009; Yuan et al. 2015). As a dominant pattern of low-frequency variability in the winter season, the WP pattern may cause the pulsing or meridional displacement of the Pacific storm track

Supplemental information related to this paper is available at the Journals Online website: https://doi.org/10.1175/JCLID-17-0618.s1.

\footnotetext{
${ }^{\text {a }}$ Current affiliation: Max Planck Institute for Meteorology, Hamburg, Germany.
}

Corresponding author: Benkui Tan, bktan@pku.edu.cn
(Nakamura et al. 1987; Lau 1988; Rogers 1990; Linkin and Nigam 2008; Wettstein and Wallace 2010; Tanaka et al. 2016); the variations of the storm track further cause sharp precipitation extremes over the Pacific and North America (Nigam 2003; Linkin and Nigam 2008; Yuan et al. 2015). The WP pattern can also impact surface air temperatures over North America, East Asia, and the Far East (Takaya and Nakamura 2005a,b; Linkin and Nigam 2008; Tanaka et al. 2016) and modulate the East Asian winter monsoon (Takaya and Nakamura 2013; Pak et al. 2014; Wang and Chen 2014). Furthermore, the WP pattern is influential on the sea ice concentration over the Sea of Okhotsk, the Bering Sea, and the Arctic Ocean (Rogers 1981; Linkin and Nigam 2008; Yuan et al. 2015).

As a low-frequency wave train, the WP pattern may exert remarkable influence on the stratospheric variability through modulating upper-tropospheric planetary waves and their upward propagation into the stratosphere (Cheng and Dunkerton 1995). The positive WP pattern (where the subpolar anomaly is cyclonic, see Fig. 1a) interferes constructively with the climatological wavenumber-1 waves. Consequently, the upwardpropagating wave activity fluxes into the stratosphere are enhanced. As a result, the polar vortex weakens and 

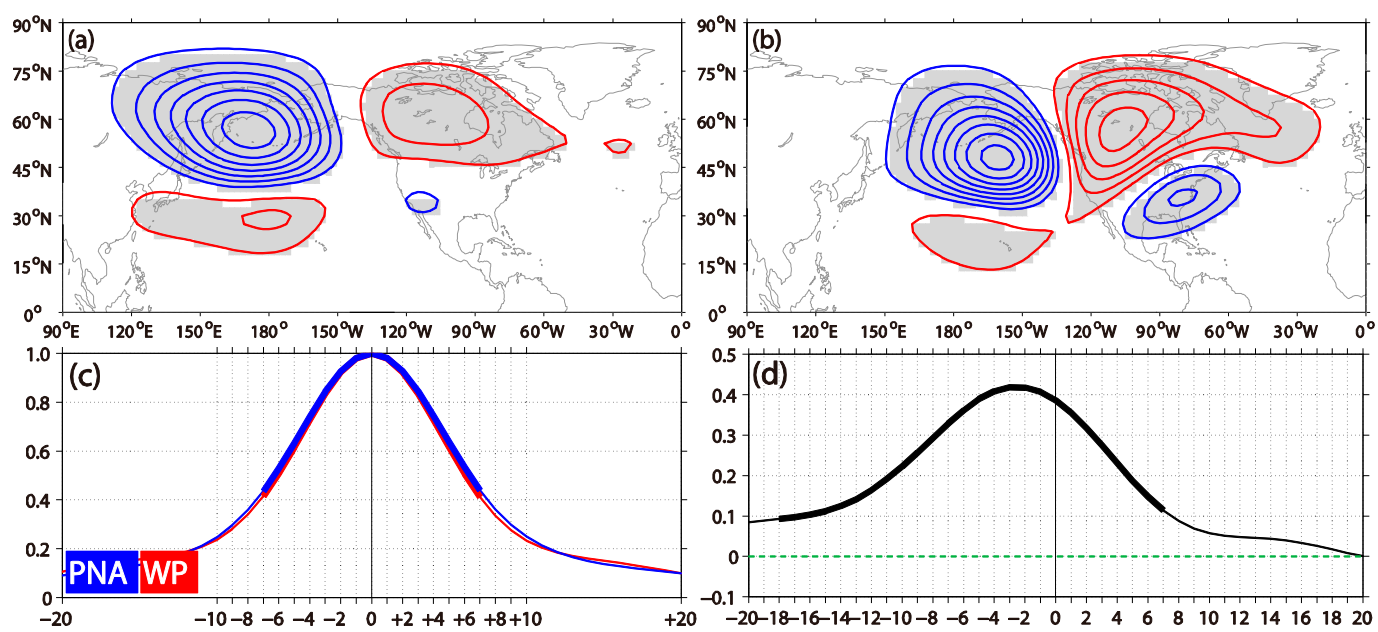

FIG. 1. Regressions of low-pass-filtered 250-hPa geopotential height anomalies onto (a) WPI and (b) PNAI. Red (blue) contours indicate positive (negative) values. Contours start from $\pm 20 \mathrm{~m}$ with an interval of $20 \mathrm{~m}$ and zero lines are omitted. Shading indicates the anomalies that are statistically significant at the $p<0.01$ level, as determined with a two-tailed Student's $t$ test. (c) Autocorrelations of WPI (red) and PNAI (blue). Thick curves correspond to the time it takes for the autocorrelation function to decay by a factor of $e$. (d) Cross correlation between WPI and PNAI. Thick curves indicate the values that are statistically significant at the $p<0.01$ level, as determined with a two-tailed Student's $t$ test. Negative lags denote PNAI leading WPI.

warms. Occasionally, the polar vortex completely breaks down and a major stratospheric sudden warming (SSW) occurs (Nishii et al. 2011; Dai and Tan 2016). Consistent with this, the negative WP pattern interferes destructively with the tropospheric climatological planetary wavenumber- 1 waves. As a result, the upwardpropagating wave activity fluxes into the stratosphere are reduced, which leads to the intensification and cooling of the polar vortex (Limpasuvan et al. 2005; Nishii et al. 2010; Woollings et al. 2010), as well as the expansion of an extremely cold domain over the Arctic where polar stratospheric clouds can potentially form (Orsolini et al. 2009).

As demonstrated in Wallace and Gutzler (1981), the WP pattern was as prominent as the Pacific-North American (PNA) pattern, at least in the particular period of 1962/63-76/77. However, the WP pattern has been less intensively studied than the PNA pattern (Cash and Lee 2001; Feldstein 2002; Franzke and Feldstein 2005; Mori and Watanabe 2008; Athanasiadis et al. 2010; Johnson and Feldstein 2010; Franzke et al. 2011; Dai et al. 2017). Studies by Lau (1988), Rivière (2010), and Tanaka et al. (2016) found that both the barotropic feedback from transient eddies and baroclinic energy conversion may contribute to the maintenance of the WP pattern. The numerical modeling study by Hurwitz et al. (2012) revealed that the midlatitude North Pacific sea surface temperature (SST) anomalies are favorable for the occurrence of the WP pattern. Recently, Dai and Tan (2016) found that the positive
WP pattern can develop from northwestward propagation of PNA-like geopotential height anomalies, which sheds more light on the WP-SSW relationship. These findings motivate us to investigate separately the evolution features and climate impacts of the WP patterns that are associated with or unrelated to the PNA pattern. The ENSO modulation on the WP patterns is also a subject of the present study.

\section{Data and methods}

\section{a. Data}

The present study uses daily data from the National Centers for Environmental Prediction-National Center for Atmospheric Research (NCEP-NCAR) (Kalnay et al. 1996) reanalysis. The gridded field variables at the standard pressure levels are used, which cover the extended winter seasons [November-March (NDJFM)] from 1948/49 to 2014/15. Temperature anomalies at the lowest model level of $\sigma=0.995$ just above the surface are used to describe the surface weather anomalies associated with WPs. Anomalies of surface turbulent heat fluxes (sum of the surface sensible and latent heat flux) are used to investigate the impact of anomalous winds on midlatitude SST variability. Daily anomalies at each grid point are obtained by subtracting the seasonal cycle on that calendar day from the raw daily field. The seasonal cycle is defined by the first three Fourier harmonics of the daily climatology. To extract quasi-stationary 
TABLE 1. Number of WP events detected in different ENSO phases for the extended winter (NDJFM) over 1948/49-2014/15. WENSO, CENSO and NENSO stand for the warm, cold, and neutral phases of ENSO, respectively. Values in parentheses are the frequency of occurrence (unit: events per winter). Frequency set in italic font is statistically significant at the $p<0.10$ level based on a two-tailed Monte Carlo test, while frequency set in boldface font is significantly different between WENSO and CENSO winters at the $p<0.10$ level based on a two-tailed Monte Carlo test.

\begin{tabular}{|c|c|c|c|c|}
\hline 1948/49-2014/15 & All winters & $\mathrm{WENSO}^{\mathrm{a}}$ & $\mathrm{CENSO}^{\mathrm{b}}$ & $\mathrm{NENSO}^{\mathrm{c}}$ \\
\hline PNA-free WP+ & $49(0.73)$ & $17(0.74)$ & $15(0.68)$ & $17(0.77)$ \\
\hline PNA-preceded WP+ (I) & $37(0.55)$ & $22(0.96)$ & $7(0.32)$ & $8(0.36)$ \\
\hline PNA-preceded WP+ (II) & $19(0.28)$ & $8(0.35)$ & $8(0.36)$ & $3(0.14)$ \\
\hline PNA-free WP- & $31(0.46)$ & $11(0.48)$ & $11(0.50)$ & $9(0.41)$ \\
\hline PNA-preceded WP- (I) & $37(0.55)$ & $9(0.39)$ & $14(0.64)$ & $14(0.64)$ \\
\hline PNA-preceded WP- (II) & $18(0.27)$ & $10(0.43)$ & $5(0.23)$ & $3(0.14)$ \\
\hline
\end{tabular}

${ }^{a}$ The 23 WENSO winters are 1952/53, 1953/54, 1957/58, 1958/59, 1963/64, 1965/66, 1968/69, 1969/70, 1972/73, 1976/77, 1977/78, 1979/80, 1982/83, 1986/87, 1987/88, 1991/92, 1994/95, 1997/98, 2002/03, 2004/05, 2006/07, 2009/10, and 2014/15.

${ }^{\mathrm{b}}$ The 22 CENSO winters are 1949/50, 1950/51, 1954/55, 1955/56, 1964/65, 1967/68, 1970/71, 1971/72, 1973/74, 1974/75, 1975/76, 1984/85, 1988/89, 1995/96, 1998/99, 1999/00, 2000/01, 2005/06, 2007/08, 2008/09, 2010/11, and 2011/12.

${ }^{c}$ The 22 NENSO winters are 1948/49, 1951/52, 1956/57, 1959/60, 1960/61, 1961/62, 1962/63, 1966/67, 1978/79, 1980/81, 1981/82, 1983/84, 1985/86, 1989/90, 1990/91, 1992/93, 1993/94, 1996/97, 2001/02, 2003/04, 2012/13, and 2013/14.

fluctuations associated with WP, a 101-point low-pass Lanczos filter (Duchon 1979) with a nominal frequency cutoff period of 10 days is applied.

Monthly (1948/49-2014/15) Extended Reconstructed SST, version 4 (ERSST.v4), data (Huang et al. 2015; Liu et al. 2015) is also used. The ENSO phases are defined based on the ERSST.v4 SST anomalies in the Niño-3.4 region $\left(5^{\circ} \mathrm{S}-5^{\circ} \mathrm{N}, 120^{\circ}-170^{\circ} \mathrm{W}\right)$. For El Niño (La Niña) winters, December-February-mean Niño-3.4 index must surpass the $+0.5^{\circ} \mathrm{C}\left(-0.5^{\circ} \mathrm{C}\right)$ threshold. Based on this threshold, there are $23 \mathrm{El}$ Niño [warm ENSO phase (WENSO)] winters, 22 La Niña [cold ENSO phase (CENSO)] winters, and 22 neutral [neutral ENSO phase (NENSO)] winters, see Table 1. For the entire 67-winter period (1948/49-2014/15), daily SST anomalies are constructed from linear interpolation of the monthly ERSST.v4 data.

\section{b. Definitions of the WP and PNA pattern}

Following Kodera (1998) and Nishii et al. (2010), the WP pattern in this study refers to the leading empirical orthogonal function (EOF) of monthly mean nonstandardized anomaly fields of $250-\mathrm{hPa}$ geopotential height for the winters from $1948 / 49$ to $2014 / 15$ over the domain $20^{\circ}-70^{\circ} \mathrm{N}, 120^{\circ} \mathrm{E}-180^{\circ}$. The positive phase of WP is defined as the situation where the subpolar anomaly is cyclonic (Fig. 1a). The daily WP index (WPI) is obtained by projecting the daily 10 -day low-pass-filtered $250-\mathrm{hPa}$ geopotential height anomaly fields onto the WP pattern. Similarly, the PNA pattern refers to the leading EOF of monthly nonstandardized anomaly fields of $250-\mathrm{hPa}$ geopotential height for the winters from 1948/49 to $2014 / 15$ over the domain $20^{\circ}-70^{\circ} \mathrm{N}, 180^{\circ}-70^{\circ} \mathrm{W}$, and the positive phase of PNA refers to the situation where the
Aleutian anomaly is cyclonic (Fig. 1b). The daily PNA index (PNAI) is obtained by projecting the daily 10-day low-pass-filtered $250-\mathrm{hPa}$ geopotential height anomaly fields onto the PNA pattern.

As indicated by the autocorrelations of WPI and PNAI (Fig. 1c), both WP and PNA have an $e$-folding time scale of 7 days, which is consistent with previous studies that teleconnection patterns have an intrinsic time scale of 2 weeks (Feldstein 2000; Cash and Lee 2001; Feldstein 2002; Mori and Watanabe 2008; Johnson and Feldstein 2010; Franzke et al. 2011; Yuan et al. 2015). The lead-lag correlation between WPI and PNAI (Fig. 1d) further indicates that the two patterns are closely correlated, especially when PNA leads WP. In view of the fact that PNA and WP have similar spatial structures located at different places (Fig. 1, top panels), this WP-PNA relation suggests that WP may develop from a preceding PNA when PNA develops westward, which will be examined in the next section.

\section{c. Definition and classification of WP events}

This study will examine the evolution features and climate impacts of WP through lagged-composite analyses based on WP events (WPs). Here a WP event of positive (negative) polarity is defined if the standardized WPI exceeds $1.0(-1.0)$ standard deviations at least for 4 consecutive days. The day of the peak WPI is denoted as day 0 . Taking the life span of WPs into consideration, two WP events of the same phase must be at least 15 days apart to ensure the independence of the samples; otherwise, the weaker event is discarded. The PNA events (PNAs) are defined in a similar way. In this study, a WP event is considered to be preceded by a PNA event if day 0 of the PNA event occurs between 15 
and 5 days prior to the day 0 of the WP event; otherwise, the WP event is considered to be independent of the PNA event for its development. This study examines only those WPs that are preceded by or not preceded by PNAs, without taking those followed by PNAs into consideration.

As a result, we have identified $191 \mathrm{WP}$ events in total for the study period. Among these 191 WP events, 80 events are not preceded by PNAs (hereafter denoted as PNA-free WPs) and 111 events are preceded by PNAs (hereafter denoted as PNA-preceded WPs) (see first column of Table 1 and Fig. S1 in the supplemental material). Table 1 (first column) further indicates that for PNA-preceded WPs, two-thirds (74 events) are preceded by PNAs with the same polarity as that of the WPs (PNA-preceded WPs-I); one-third of them (37 events) are preceded by PNAs with the polarity opposite to that of the WPs (PNA-preceded WPs-II). It turns out that PNA-free WPs, PNA-preceded WPs-I, and PNApreceded WPs-II have very different evolution features and climate impacts, as will be shown in the following sections.

\section{d. Statistical analysis}

Several of the calculations performed in this study use linear correlations/regressions. The method that we use to evaluate statistical significance for linear correlations/ regressions follows that of Kosaka et al. (2012), where the effective degrees of freedom $N_{\text {eff }}$ corresponds to

$$
N_{\text {eff }}=N /\left\{1+2 \sum_{\tau}(1-\tau / N)\left[r_{x}(\tau) r_{y}(\tau)\right]\right\},
$$

where $N$ is length of time series $X$ and $Y$, and $r_{x}$ and $r_{y}$ are the corresponding autocorrelation functions for $X$ and $Y$, respectively, with a lag of $\tau$ days.

Statistical significance of the composite analysis in this study is assessed with a Monte Carlo test by calculating 1000 randomly generated composites, with the number of composites being the same as the number of WP events. To test statistical significance, the observed composite is compared to the distribution of randomly generated composites.

The statistical test is two tailed in this study except for the composites of WPI and PNAI. As one sign for the index is to be expected (e.g., when we composite the WPI based on the positive-phase WP events, positive values are expected), a one-tailed test is used.

\section{Evolution features of WPs}

Shown in Figs. 2-4 are lagged composites of the anomalous 250-hPa geopotential heights (contours) based on the three categories and two phases of WP events listed in the first column of Table 1. Arrows in these figures are the wave activity fluxes that indicate the directions of the energy propagation of the wave train (Plumb 1985; Karoly et al. 1989). Here the term "wave train" refers to a chain of positive and negative geopotential height anomalies. We now examine the six cases of WPs separately.

\section{a. PNA-free WPS}

The PNA-free WPs, either positive or negative phases, arise from weak disturbances over Asia and the North Pacific (Fig. 2). For the composite of positive WPs (Fig. 2, left panels), initial weak disturbances are found to occur at around day -15 with the two upstream anomalies located at Lake Baikal and southeast China, and the two downstream anomalies centered at the Aleutian Islands and near the Hawaii Islands. From day -12 onward, the anticyclonic anomaly over northwest Russia begins to amplify and to disperse energy eastward, followed by the amplification of the two upstream anomalies, which merge with the two downstream anomalies at day -6 . Under persistent energy dispersion from the anticyclonic anomaly, the merged disturbances grow rapidly and evolve into a meridional dipole-like structure with the cyclonic anomaly in the north, which constitutes the two Pacific centers of the WP pattern (day -3). The full WP pattern establishes at day 0 . Then, it begins to decay. The meridional dipolar structure over the North Pacific for the positive WP pattern from day -15 to day -6 in Fig. 2 (left panels) is reminiscent of the study by Rivière (2010), which revealed that WP anomalies close to the positive phase preexist before the rapid growth of the positive WP pattern.

For the composite of negative WPs (Fig. 2, right panels), an initial quadrupole-like disturbance occurs at around day -9 . The two upstream anomalies are located at Siberia and northeast China, and the two downstream anomalies are of opposite signs and much weaker than their upstream counterparts at the same time. At around day -6 , the two upstream anomalies begin to disperse energy downstream, leading to the amplification of the two downstream centers, which constitute the two Pacific centers of the WP pattern at day -3 . The WP pattern matures at day 0 and begins to decay afterward.

A careful examination of Fig. 2 (day -6) shows that the upstream wave train bears considerable resemblance to the conventional Eurasian (EU) pattern (Wallace and Gutzler 1981; Liu et al. 2014; hereafter denoted as EU, extracted following Liu et al. 2014). Further PNA-free WPs composites of the EU indices (Fig. S2) show that, from day -10 to -3 , there are significant positive (negative) EU anomalies preceding the positive (negative) 

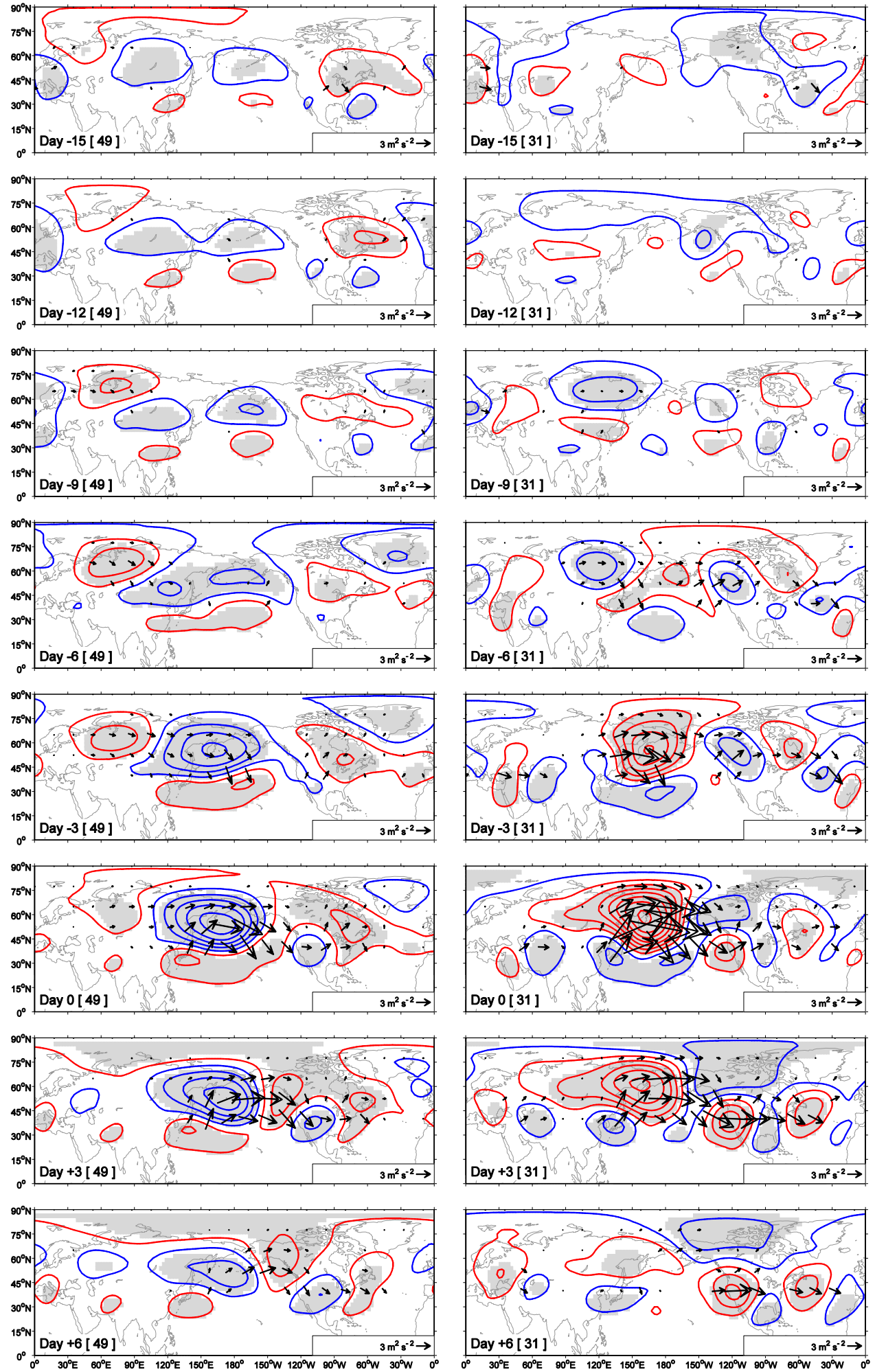

FIG. 2. Lagged composites of anomalous low-pass-filtered 250-hPa geopotential height for PNA-free WP events. Composites are performed for the period from lag day -15 to day +6 : for (left) positive and (right) negative WP phase. Red (blue) contours indicate positive (negative) values. Contours start from $\pm 20 \mathrm{~m}$ with an interval of $40 \mathrm{~m}$ and zero lines are omitted. Shading indicates the anomalies that are statistically significant at the $p<0.10$ level based on a two-tailed Monte Carlo test. Wave activity fluxes displayed are statistically significant at the $p<0.10$ level, at least for one component on a two-tailed Monte Carlo test. Scaling for the wave activity fluxes is given at the bottom-right corner for each panel $\left(\mathrm{m}^{2} \mathrm{~s}^{-2}\right)$. 

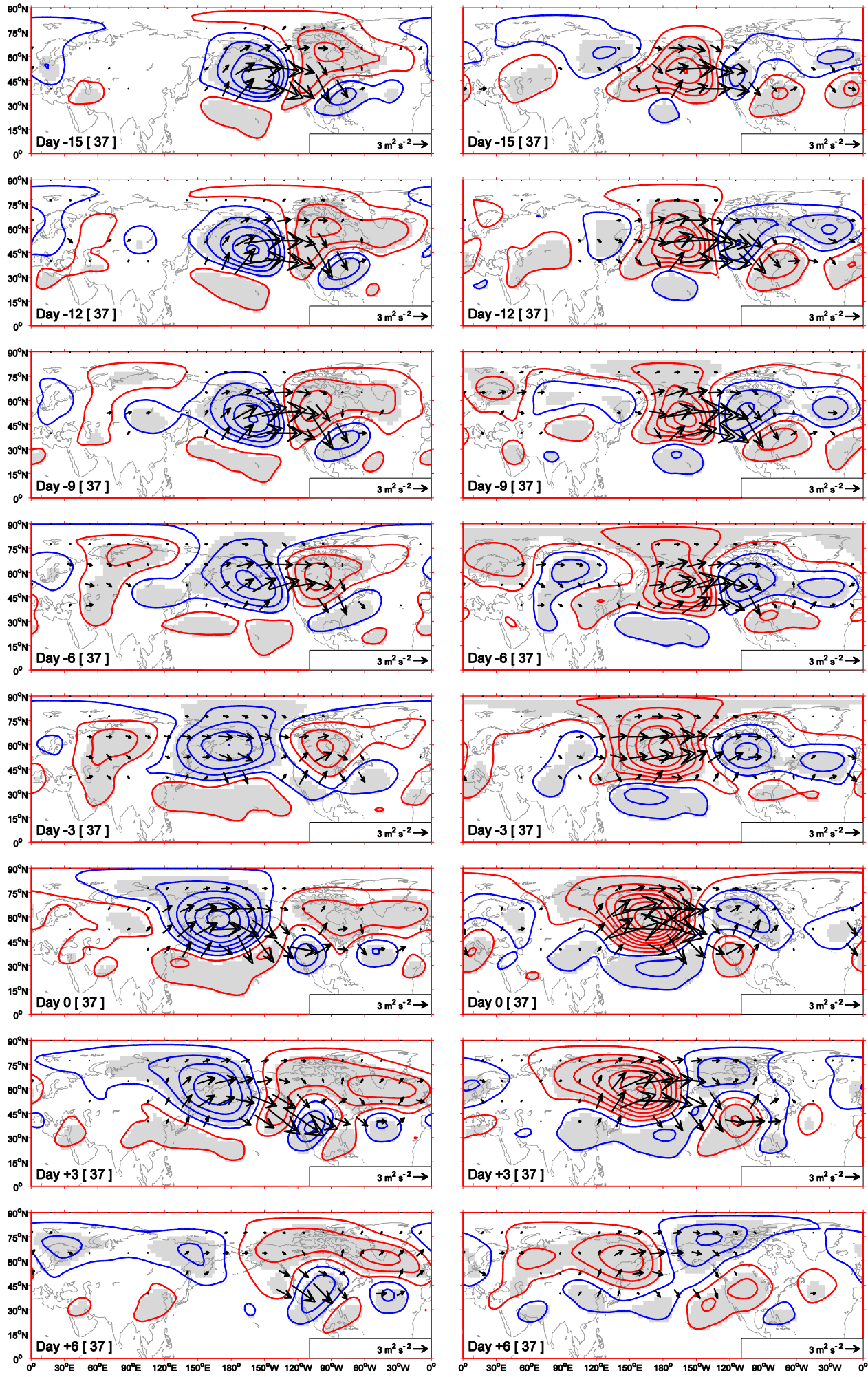

FIG. 3. As in Fig. 2, but for PNA-preceded WP-I. 

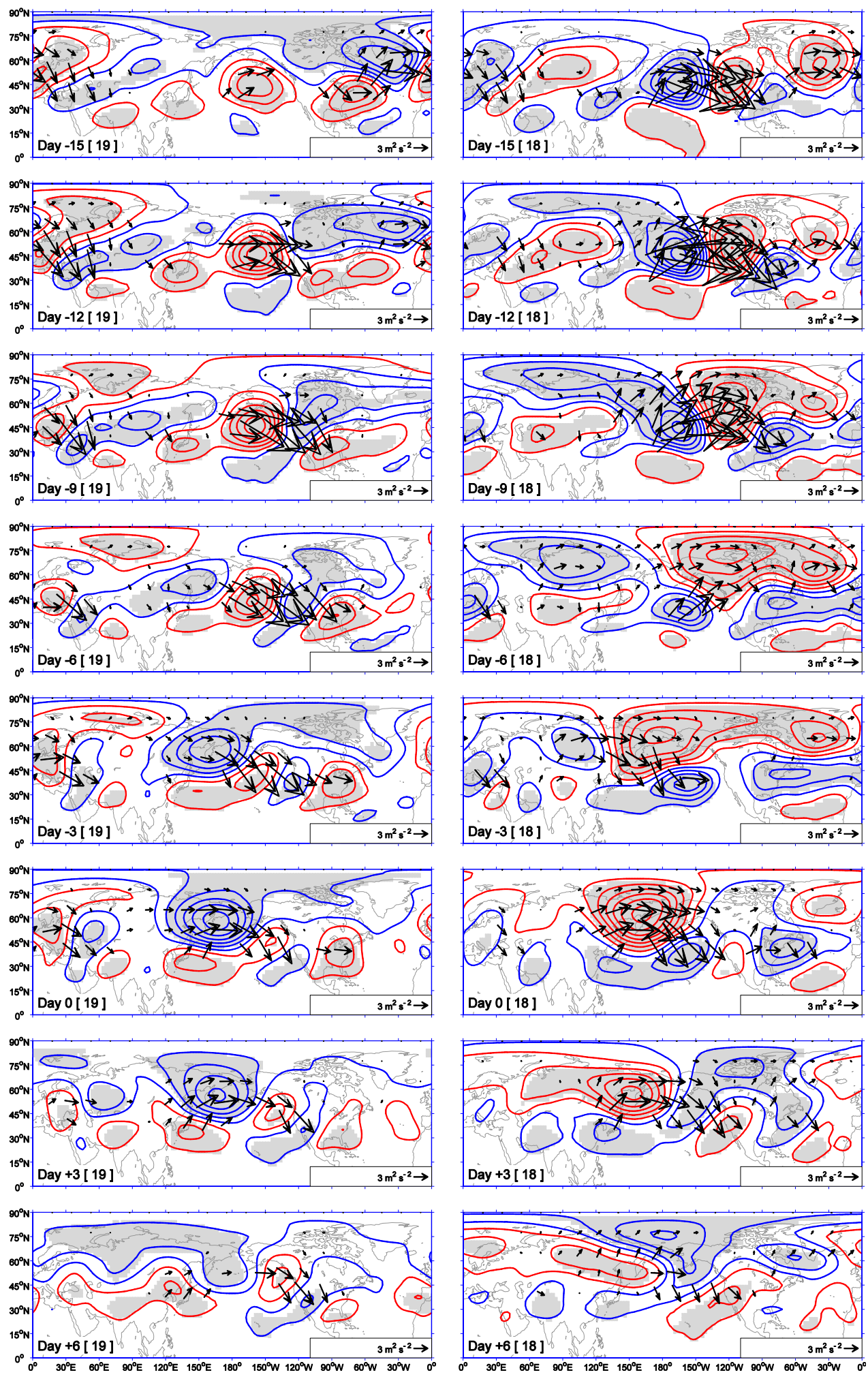

FIG. 4. As in Fig. 2, but for PNA-preceded WP-II. 
PNA-free WPs, implying EU's potential downstream predictive capacity for the PNA-free WP pattern.

\section{b. PNA-preceded WPs-I}

For PNA-preceded WPs-I, they develop from PNAlike anomalies with the same polarity as that of WPs (Fig. 3). These PNA-like anomalies have existed for a period before they evolve into the WPs. For the positive PNA-preceded WPs-I, the PNA-like anomalies occur at around day -24 (available upon request); for the negative PNA-preceded WPs-I, the PNA-like anomalies occur at around day -16 (available upon request). These PNA-like anomalies remain quasi-stationary until day -6 . From day -6 on, they begin to develop northwestward, and evolve into the WP pattern at day 0 (Fig. 3). It should be noted that the westward development of the PNA-like anomalies was also found in Kushnir (1987).

\section{c. PNA-preceded WPs-II}

As shown in Fig. 4, the WP patterns can also develop from PNA-like anomalies with the opposite polarity to that of WPs. The wave source region over the North Atlantic sector (day -15) is reminiscent of the potential role of the North Atlantic in forcing the formation of the PNA pattern, as has been revealed in Baxter and Nigam (2013). The PNA-like anomaly establishes at day -12 (day -15) for positive (negative) WPs. Both anomalies mature at around day -9 , and then evolve into the WP patterns with the aid of wave trains over Eurasia. For the positive PNA-preceded WPs-II (Fig. 4, left panels), the wave train over Eurasia is active from day -12 to day -6 . From day -6 to day -3 , the two centers at central Asia and Japan of the wave train amplify and evolve into the two Pacific centers of the WP pattern. At the same time, the Aleutian anticyclonic center of the PNA pattern begins to weaken and move eastward, which evolves into the downstream center of the WP pattern (day 0). For the negative PNA-preceded WPs-II (Fig. 4, right panels), from day -9 on, the Aleutian cyclonic center of the PNA-like anomaly weakens and moves equatorward slowly; at the same time, the North American anticyclonic center amplifies and move westward. The two centers evolve into the two Pacific centers of the WP pattern at day -3 , which undergo further amplification via the energy dispersion from the wave train over Eurasia. The full WP pattern establishes at day 0 , and it begins to decay afterward (Fig. 4, right panels).

\section{Climate impacts of WPs}

This section examines the impacts of WP pattern on the near-surface and polar stratospheric air temperatures.

\section{a. Near-surface air temperature anomalies}

Figure 5 shows composites of surface air temperature (SAT) anomalies associated with the six cases of WPs examined above. The composites are performed based on the period from day -7 to day +7 , which covers roughly the life spans of the WPs. For PNA-free WPs, the SAT anomalies take the form of a zonal-dipole structure (Fig. 5, top panels). The positive PNA-free WPs cause cooling over the Far East and warming over northern North America (Fig. 5a). The lower-layer wind system for this case is a strong anomalous cyclone. As can be seen, the cooling over the Far East is associated with the cold advection by northeasterly winds from the polar cap, and the warming over northern North America is a result of warm advection by southwesterly winds from the ocean. The opposite is true for the negative PNA-free WPs (Fig. 5d). The lower-layer wind system for this case is an anomalous anticyclone. The cooling over northern North America is caused by the cold advection by northwesterly winds from the polar cap, and the warming over the Far East is associated with the warm advection by southeasterly winds from the ocean.

The SAT anomalies for the PNA-preceded WPs-I also take the form of a zonal-dipole structure (Fig. 5, middle panels), whereas the SAT anomalies are much stronger for this case relative to those associated with PNA-free WPs. One possible cause for this difference is that the near-surface wind systems are more expansive and much stronger for PNA-preceded WPs-I than for PNA-free WPs (Fig. 5, middle and top panels). The other potential cause is that for PNA-preceded WPs-I, the WP and the preceding PNA patterns are of the same polarity, and thus induce SAT anomalies of the same sign over North America (Fig. 5, top panels; Fig. S3, middle panels). As a result, the SAT anomalies associated with the WP pattern further build up the anomalies over North America caused by the preceding PNA pattern.

In contrast, for PNA-preceded WPs-II, the SAT anomalies assume a monopole structure over the Far East, and the anomalies over North America almost disappear (Fig. 5, bottom panels). The Far East SAT anomalies induced by PNA-preceded WPs-II (Fig. 5, bottom panels), which are comparable to those caused by PNA-free WPs (Fig. 5, top panels), are much weaker relative to those associated with PNA-preceded WPs-I (Fig. 5, middle panels). This is because the lower-layer anomalous cyclone (anticyclone) is weaker in intensity and smaller in size for PNA-preceded WPs-II than for PNA-preceded WPs-I. The cause for the absence of the SAT anomalies over North America may be that the SAT anomalies over this region caused by the WP pattern and by the preceding PNA pattern are of opposite signs and thus they cancel each other out (Fig. 5, top panels; Fig. S3, bottom panels). 

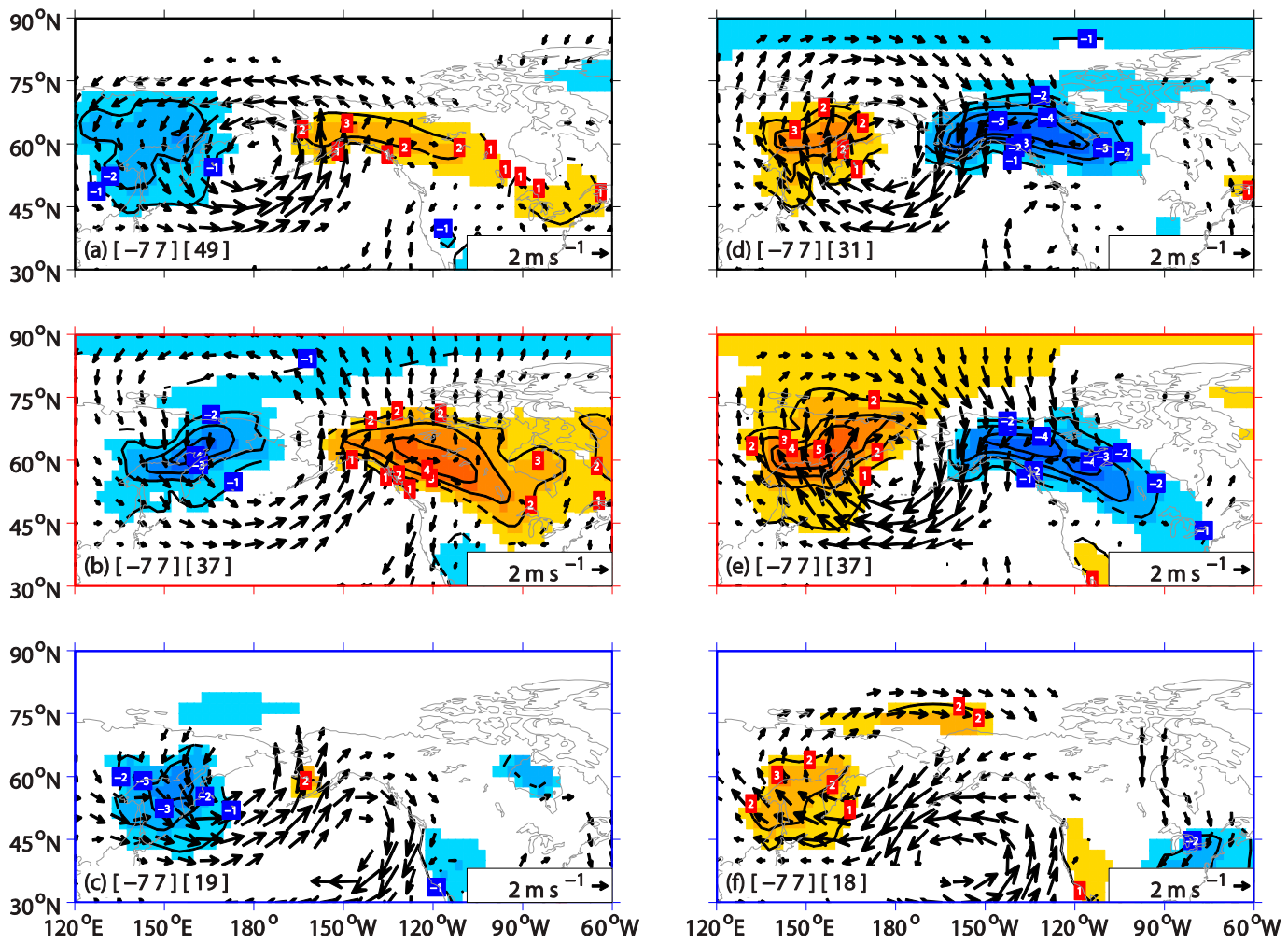

FIG. 5. Composite anomalous low-pass-filtered temperature at the level of $\sigma=0.995$ (contours and shading) and horizontal winds (arrows) at $850 \mathrm{hPa}$ for (a),(d) PNA-free WP, (b),(e) PNA-preceded WP-I, and (c),(f) PNApreceded WP-II averaged over the mature stage from day -7 to day +7 . Warm (cool) shading indicates positive (negative) anomalies. Contours start from $\pm 1 \mathrm{~K}$ with an interval of $1 \mathrm{~K}$ and zero lines are omitted. Temperature anomalies displayed are statistically significant at the $p<0.10$ level based on a two-tailed Monte Carlo test. Winds displayed are statistically significant at the $p<0.10$ level for at least one component on a two-tailed Monte Carlo test. Scaling for the winds is given at the bottom-right corner for each panel $\left(\mathrm{m} \mathrm{s}^{-1}\right)$. Plots are for (left) the positive and (right) the negative WP phase.

\section{b. Polar stratospheric air temperature anomalies}

As mentioned earlier, previous studies (Nishii et al. 2010, 2011; Dai and Tan 2016) show that the positive (negative) WP patterns may cause warming (cooling) of the polar stratosphere through constructively (destructively) interacting with the climatological planetary waves in the troposphere and thus enhancing (reducing) the wave activity fluxes into the stratosphere. In this study, we define the lifetime of a WP event as corresponding to the time period over which its amplitude is statistically significant at the $p<0.01$ level. As shown in Fig. 6, for the positive WPs, the duration is much longer for PNA-preceded WPs-I than for the other two categories (Fig. 6a). Similarly, for the negative WPs, the duration is longer and the amplitude is considerably larger for PNA-preceded WPs-I than for the other two categories (Fig. 6d). Consistently, for the positive (negative) WPs, the enhancement (reduction) of upward wavenumber-1 wave activity fluxes into the stratosphere is much stronger for PNA-preceded WPs-I than for the other two categories (Fig. 6, middle panels). Consequently, the warming (cooling) of the stratospheric polar cap is much stronger for PNA-preceded WPs-I, compared to the other two categories (Fig. 6, bottom panels). For PNA-preceded WPs-I, the warming in the stratosphere induced by the positive WPs reaches its maximum at around day +7 and persists beyond day +20 (Fig. 6c); the cooling caused by the negative WPs occurs at around day +5 and persists beyond day +20 as well (Fig. 6f).

\section{The ENSO modulation}

How ENSO influences the WP pattern is a subject of great scientific interest for the meteorology and climate communities (Horel and Wallace 1981; Kodera 1998; Yu and Kim 2011; Dai and Tan 2016; Tanaka et al. 2016). Horel and Wallace (1981) and Kodera (1998) showed that warm SST episodes in the central equatorial Pacific 

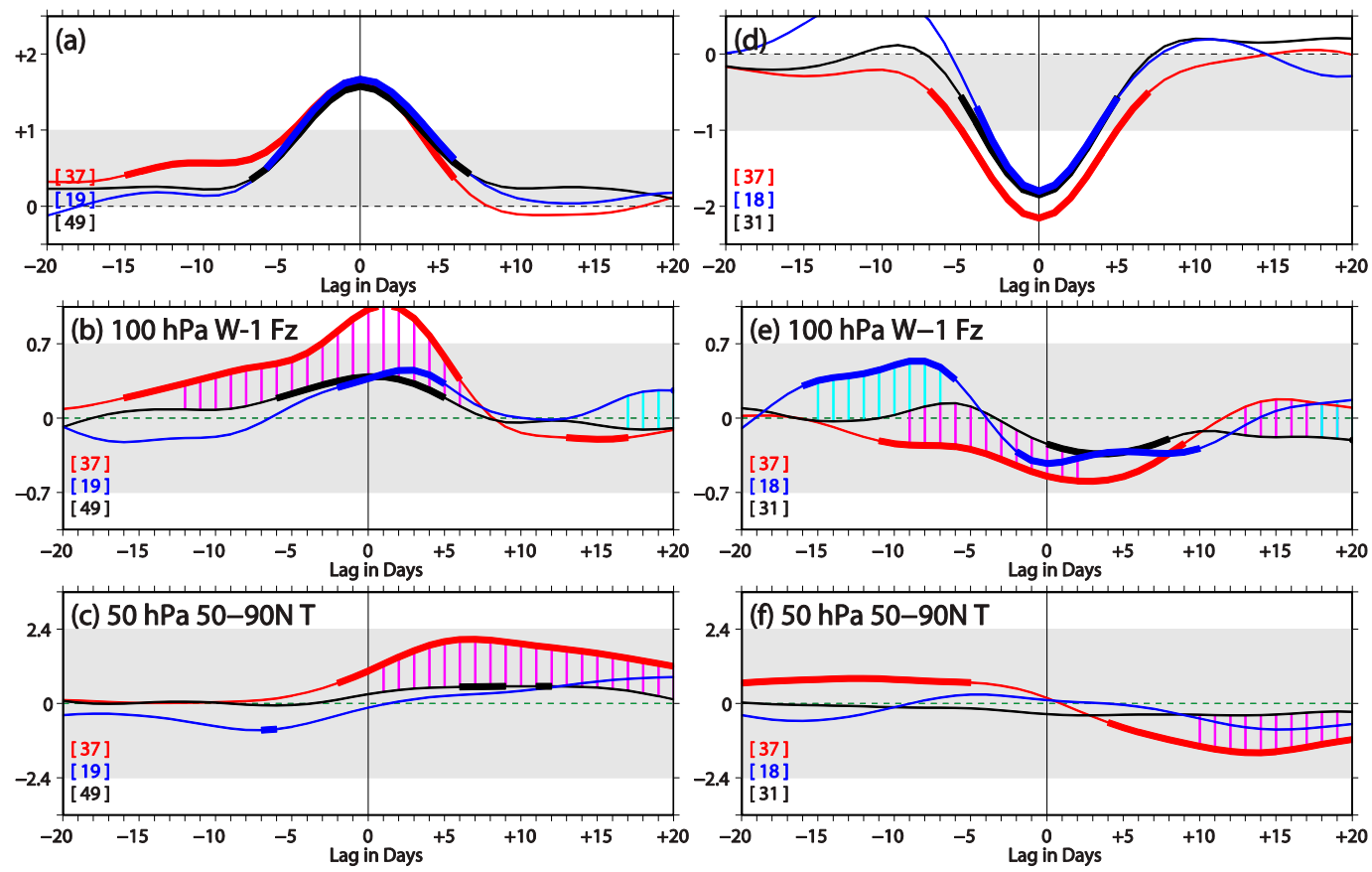

FIG. 6. Lagged-composites of (a),(d) the normalized WP indices, (b),(e) vertical component of wavenumber-1 planetary wave activity fluxes $\left(\mathrm{FZ} ; \mathrm{m}^{2} \mathrm{~s}^{-2}\right.$ ) at $100 \mathrm{hPa}$, and (c),(f) polar cap (north of $50^{\circ} \mathrm{N}$ )-averaged temperature anomalies (K) at $50 \mathrm{hPa}$. Black, red, and blue curves correspond to PNA-free WP, PNA-preceded WP-I, and PNApreceded WP-II, respectively. FZ values are area averaged between $45^{\circ}$ and $75^{\circ} \mathrm{N}$. Note that the values of $\mathrm{FZ}$ have been multiplied by a factor of 100 for a better graphical display. Thick curves in the top row correspond to the values that are statistically significant at the $p<0.01$ level based on a one-tailed Monte Carlo test. Thick curves in the middle and bottom rows correspond to the values that are statistically significant at the $p<0.10$ level based on a two-tailed Monte Carlo test. Black vertical line denotes day 0 for WP events. Dashed horizontal line indicates the climatology and gray shading denotes the positive (negative) one standard deviation range above (below) the climatology. Magenta (cyan) vertical lines correspond to the values that are significantly different between PNApreceded WP-I (PNA-preceded WP-II) and PNA-free WP at the $p<0.10$ level on a two-tailed Monte Carlo test. Plots are for (left) the positive and (right) the negative WP phase.

tend to be accompanied by well-defined teleconnection patterns, which contain elements of the PNA and WP patterns, exhibiting below-normal heights in a broad belt across the North Pacific extending westward into Siberia. They also showed that the WP pattern is more closely related to ENSO than the PNA pattern. Recently, Tanaka et al. (2016) showed that there is a tendency for a low probability of occurrence of a negative (positive) phase of WPs during El Niño (La Niña) winters. These studies, however, do not distinguish between the different types of WPs. We here examine the ENSO-WP relation for PNA-free WPs and PNA-preceded WPs-I separately, with PNA-preceded WPs-II being excluded from the discussion because of the limited sample size.

We start with the impact of ENSO on the frequency of occurrence of WPs. For PNA-free WPs, ENSO shows no apparent impacts on their frequency of occurrence, based on the first and fourth rows in Table 1. For PNApreceded WPs-I, ENSO impacts on their frequency of occurrence are significant (Table 1, second and fifth rows). The positive PNA-preceded WPs-I occur more often during WENSO winters (0.96 events per winter) than during CENSO winters (0.32 events per winter), the difference of which is statistically significant at the $p<0.10$ level on a two-tailed Monte Carto test. Consistent with this, the negative PNA-preceded WPs-I occur less often in WENSO winters (0.39 events per winter), comparing with climatology ( 0.55 events per winter), which is also statistically significant at the $p<$ 0.10 level on a two-tailed Monte Carto test. Therefore, the tendency of low probability of occurrence of a negative (positive) phase of WP during El Niño (La Niña) winters demonstrated in Tanaka et al. (2016) may be mainly attributed to the modulation of ENSO on PNApreceded WPs-I.

We next examine the impact of ENSO on the amplitude and the persistence of WPs. As can be seen from the lagged composite of the WP indices in Fig. 7, PNAfree WPs last for about 10 days during different ENSO phases (thick curves in Figs. 7a and 7c) with similar 

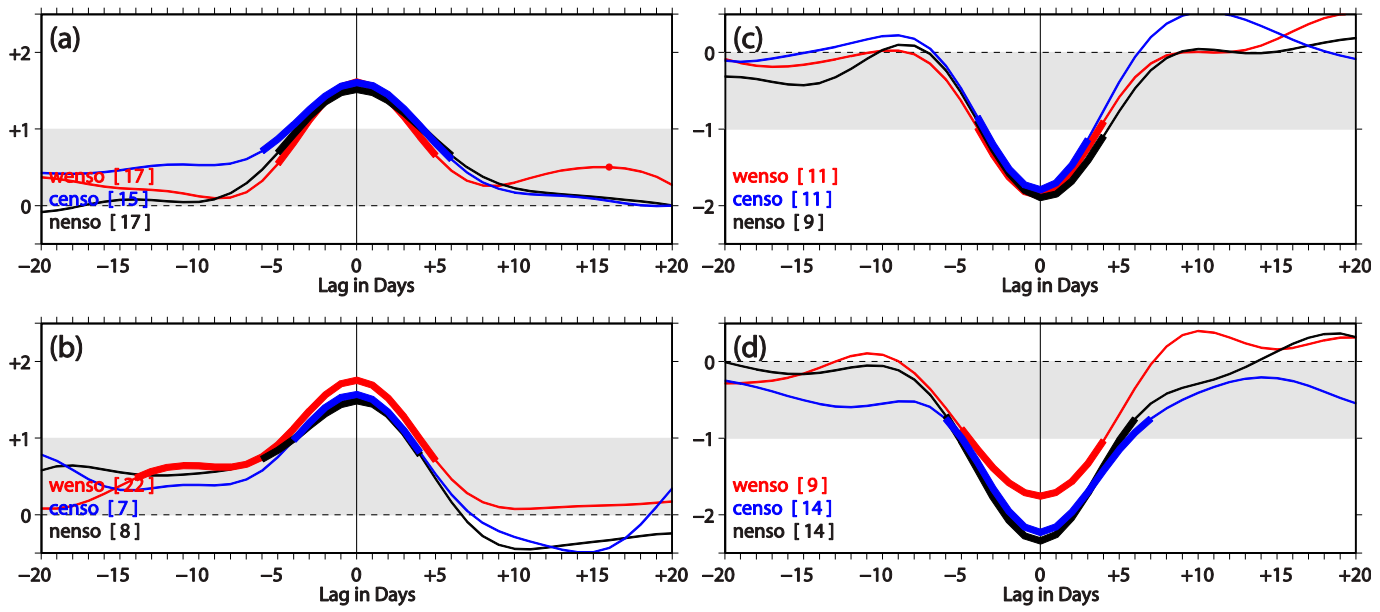

FIG. 7. Lagged composites of the normalized WP indices for different ENSO phases for (a),(c) PNA-free WP and (b),(d) PNA-preceded WP-I. Red, blue, and black curves correspond to WENSO, CENSO, and NENSO, respectively. Black vertical line denotes day 0 for WP events. Black dashed horizontal line indicates the wintertime climatology and gray shading denotes the positive (negative) one standard deviation range above (below) the climatology. Thick curves correspond to the values that are statistically significant at the $p<0.01$ level based on a one-tailed Monte Carlo test. Plots are for (left) the positive and (right) the negative WP phase.

amplitudes, indicating that ENSO has little impacts on the amplitude and the persistence of PNA-free WPs (Figs. 7a and 7c). By contrast, the ENSO impacts on the amplitude and the persistence are apparent for PNApreceded WPs-I. Specifically, for the positive PNApreceded WP-I events (Fig. 7b), the most persistent events are those occurring during WENSO winters (about 3 weeks; thick red curve in Fig. 7b); the least persistent events are those occurring during CENSO winters (about 1 week; thick blue curve in Fig. 7b). Furthermore, the former have larger amplitudes than the latter. Consistent with this, for the negative PNApreceded WP-I events (Fig. 7d), the most persistent events are those occurring during CENSO winters (about 2 weeks; thick blue curve in Fig. 7d); the least persistent events are those occurring during WENSO winters (about 10 days; thick red curve in Fig. 7d). Moreover, the former have larger amplitudes than the latter. The above results suggest that the positive PNApreceded WP-I events during WENSO winters have longer duration and larger amplitude than those during CENSO winters (Fig. 7b), which is consistent with the finding of Dai and Tan (2016). Consistently, the negative PNA-preceded WP-I events during CENSO winters have longer duration and larger amplitude than those during WENSO winters (Fig. 7d).

\section{Conclusions and discussion}

This study finds that WPs can arise from precursory disturbances over Asia and the North Pacific, or from
PNA-like anomalies of the same polarity as or opposite polarity to that of WPs. Among these WP patterns, PNA-preceded WPs-I cause strongest air temperature anomalies in the North America near surface and in the polar stratosphere; besides, they can be affected by ENSO phases: the positive phase of PNA-preceded WP-I events have higher frequencies of occurrence, longer life spans, and larger amplitudes in WENSO than in CENSO winters; consistently, the negative phase of PNA-preceded WP-I events have lower frequencies of occurrence, shorter durations, and smaller amplitudes in WENSO than in CENSO winters. It should be noted that the PNA pattern and the WP pattern can also be defined based on other approaches (e.g., Wallace and Gutzler 1981; Nigam 2003). We have tested the sensitivity of the above results to both definitions (available upon request), and it turns out that the results are not overly sensitive to the definitions of the PNA pattern and the WP pattern.

Very briefly, as has been summarized above, PNApreceded WPs-I have significant climate impacts and can be modulated by ENSO phases, which may be of particular interest for subseasonal to seasonal predictions. Therefore, for PNA-preceded WPs-I, it is important to understand the underlying physical processes that drive the conversion from the preceding PNA to the WP. To address this question, first of all, we investigate the role of the background westerlies, which are closely related to the Rossby wave phase propagation, and thus may act to drive the westward propagation of PNA-related circulation anomalies. We accomplish this 

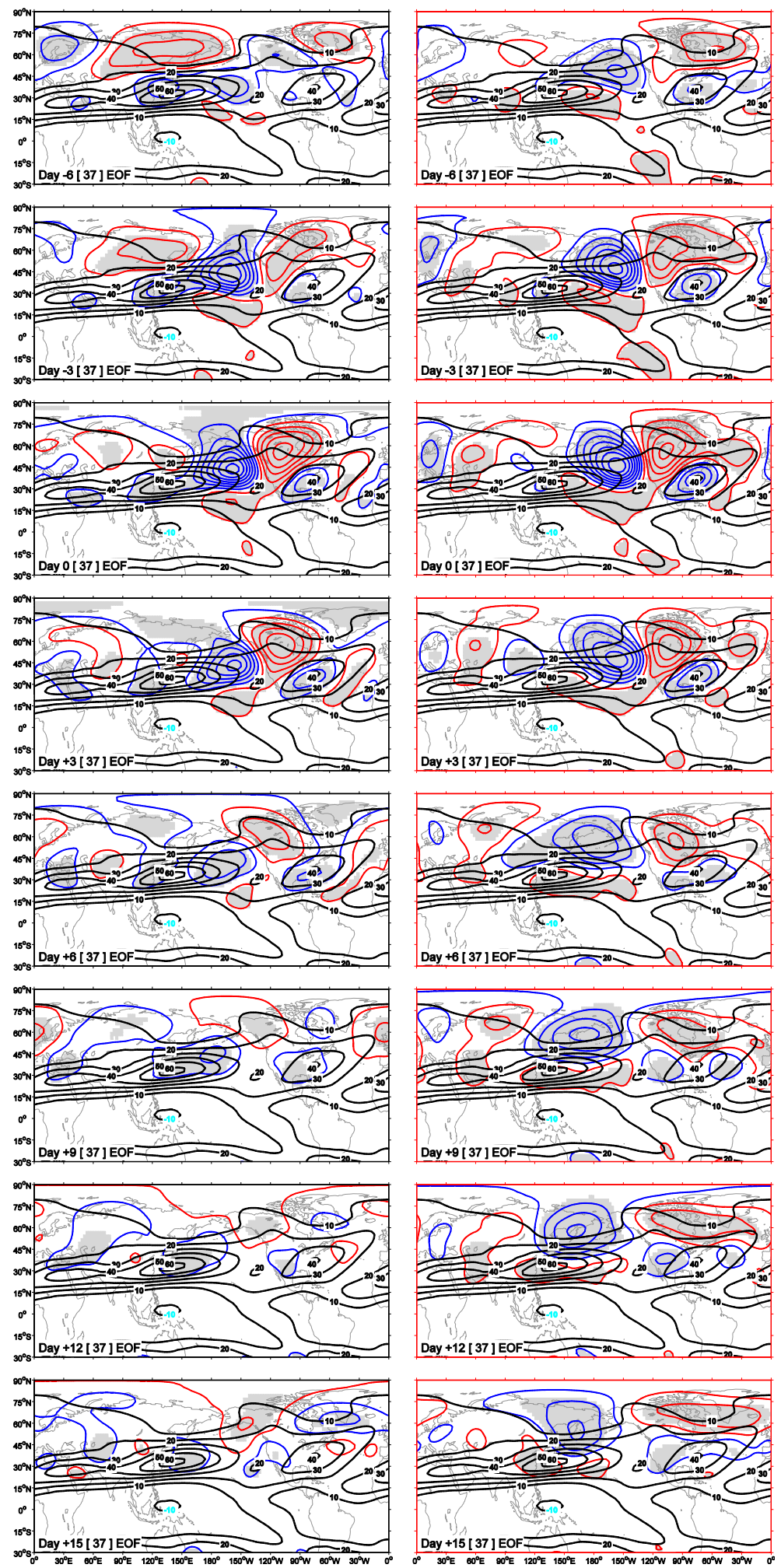

FIG. 8. Lagged composites of anomalous geopotential height (color contours) fields at $250 \mathrm{hPa}$ for the positive (left) $\mathrm{PNA}_{\mathrm{WO}}$ and (right) $\mathrm{PNA}_{\mathrm{W}}$ events. Composites are performed for the period from lag day -6 to day +15 with a time interval of 3 days. Contours start from $\pm 20 \mathrm{~m}$ with an interval of $40 \mathrm{~m}$ and zero lines are omitted. Red (blue) contours indicate positive (negative) values. Shading indicates anomalies that are statistically significant at the $p<0.10$ level based on a Monte Carlo test. Black contours denote the climatology of the zonal wind at $250 \mathrm{hPa}$. The contour interval is $10 \mathrm{~m} \mathrm{~s}^{-1}$ for the climatology of the zonal wind. 

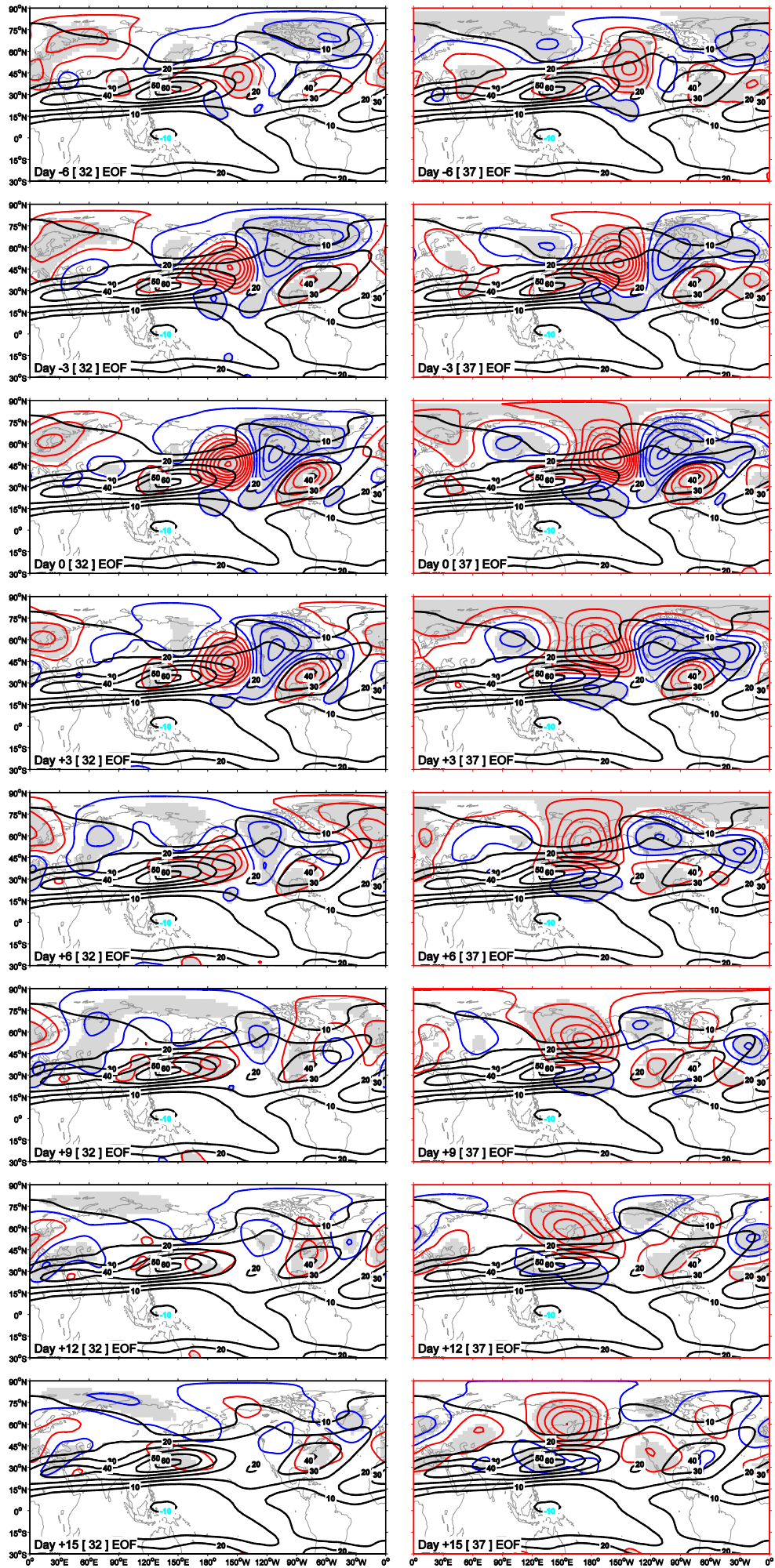

FIG. 9. As in Fig. 8, but for the negative PNA phase. 

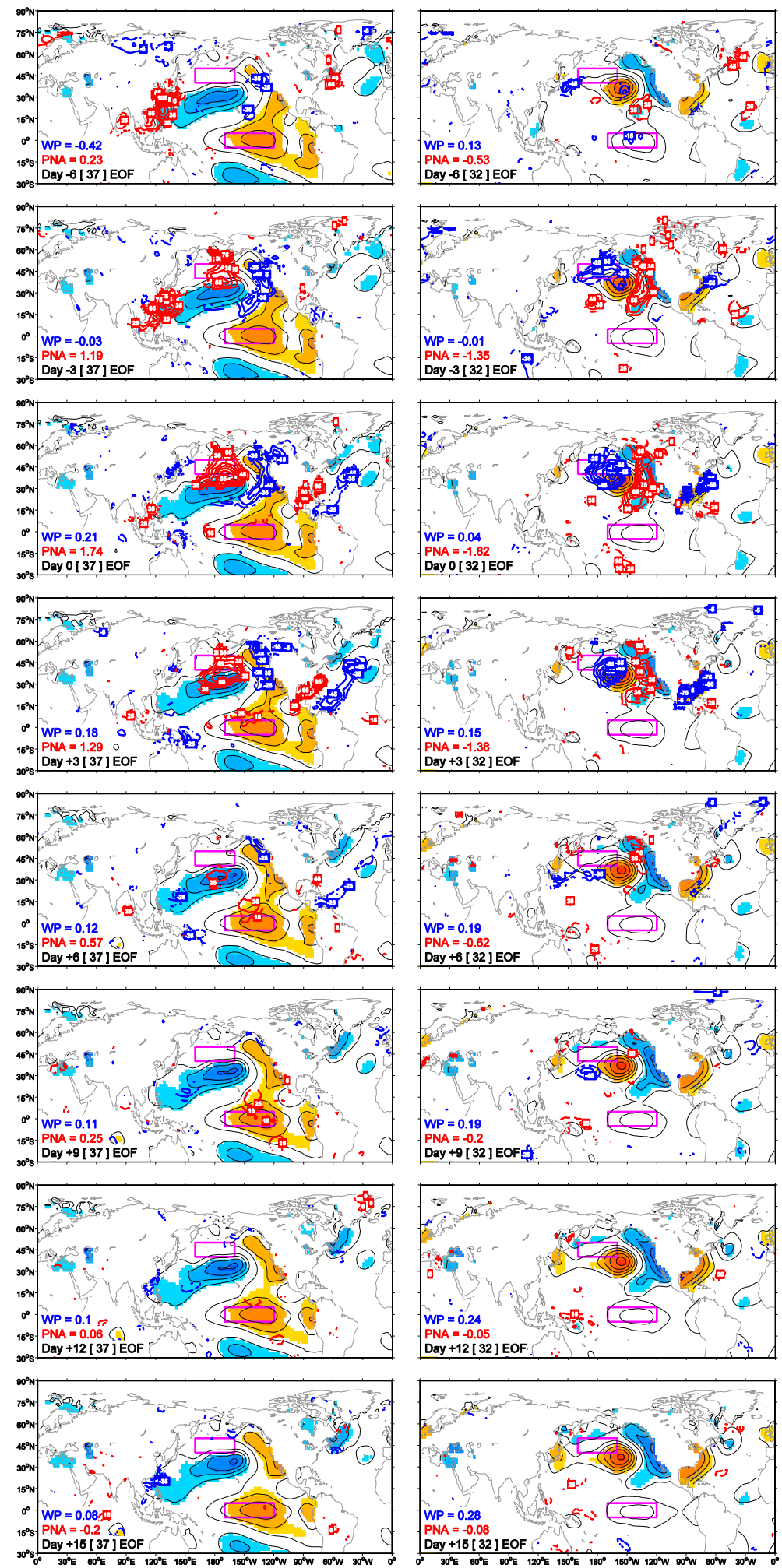

FIG. 10. Lagged composites of anomalous SST fields (black contours and color shading) and combination of sensible and latent heat fluxes at the ocean surface

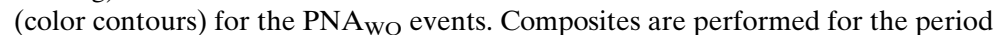
from lag day -6 to day +15 with a time interval of 3 days: (left) the positive and 
by examining, separately, the configuration of the climatological zonal wind fields and composites of geopotential height anomalies at $250 \mathrm{hPa}$ during PNA episodes with and without succeeding WPs. A PNA event is considered to precede a WP event if the WP event peaks between 5 and 15 days after the PNA event peak; otherwise, the PNA event is considered as not preceding a WP event. The former (latter) type of PNA is denoted as $\mathrm{PNA}_{\mathrm{W}}\left(\mathrm{PNA}_{\mathrm{WO}}\right)$, where the subscripts $\mathrm{W}$ (WO) represents "with" ("without") a succeeding WP. As a result, we have identified 37 positive PNA $_{W}$ events and 37 negative PNA $_{W}$ events, as well as 37 positive PNA $_{W O}$ events and 32 negative PNA WO $_{\text {events (see }}$ Table S1 and Figs. S4-S5). It is noteworthy that we only consider PNA and WP of the same polarity here. Therefore, there is a one-to-one correspondence between the PNA $_{W}$ events and the PNA-preceded WP-I events, as can be seen from their identical sample sizes and frequency distributions during different ENSO phases (Table 1 and Table S1). Shown in Figs. 8 and 9 are the anomalous geopotential height fields at $250 \mathrm{hPa}$ (color contours) for the PNA $_{\text {WO }}$ (left panels) and PNA ${ }_{W}$ (right panels) events, superimposed on the wintertime (NDJFM) climatological zonal wind fields at $250 \mathrm{hPa}$ (black contours). As can be seen, from day -6 to day 0 , for both phases of the PNA events, the upper-tropospheric circulation pattern of the PNA $_{W}$ is located to the poleward of that of the PNA ${ }_{W O}$, and thus the background westerlies of the former is weaker than that of the latter since the former is away from the jet axis. As a result, from day 0 on, the circulation anomalies of the PNA $_{W}$ events propagate slowly westward and gradually evolve into the WP-like anomalies, since the weak westerlies tend to enable a circulation anomaly to move westward due to Rossby wave phase propagation (Figs. 8 and 9, right panels). By contrast, the circulation anomalies of the $\mathrm{PNA}_{\mathrm{WO}}$ events remain quasi-stationary and decay locally (Figs. 8 and 9, left panels).

Moreover, motivated by the finding of Hurwitz et al. (2012) that SST anomalies over the North Pacific $\left(40^{\circ}-50^{\circ} \mathrm{N}, 160^{\circ}-200^{\circ} \mathrm{E}\right)$ can trigger the WP pattern, as well as the finding of Nigam (2003) that the PNA pattern can induce cumulative North Pacific SST changes during its life span, we try to understand the conversion from PNA into WP from the viewpoint of the extratropical air-sea interaction over the North Pacific. To be specific, Hurwitz et al. (2012) reveals that negative SST anomalies over the North Pacific can trigger the positive WP phase; Nigam (2003) demonstrates that the positive PNA phase can induce negative North Pacific SST anomalies. These phase correspondences allude to the potential role of the extratropical air-sea interaction over the North Pacific in the conversion from PNA into WP of the same polarity, which occurs during PNA $_{W}$ episodes. In the following, "key region" is used to represent $\left(40^{\circ}-50^{\circ} \mathrm{N}, 160^{\circ}-200^{\circ} \mathrm{E}\right)$, where SST anomalies are prescribed in the model study of Hurwitz et al. (2012). We accomplish this by examining, separately, composites of daily SST anomalies during PNA WO (Fig. 10) and PNA $_{\mathrm{W}}$ (Fig. 11) episodes, and showing that only composites based on the $\mathrm{PNA}_{\mathrm{W}}$ events exhibit significant SST anomalies over the key region. It can be seen from Fig. 10 that, during PNA WO $_{\text {episodes, there }}$ are no significant SST anomalies over the key region. By contrast, during PNA $_{\mathrm{W}}$ episodes (Fig. 11), significant SST anomalies over the key region can be observed. Specifically, for the positive PNA ${ }_{\mathrm{W}}$ composites (Fig. 11, left panels), some precursor negative SST anomalies over the key region are found to occur before the peak of the PNAs (at around day -15 , available upon request), and they intensify gradually as the PNAs grow up and decay; for the negative PNA $_{\mathrm{W}}$ composites (Fig. 11, right panels), some precursor positive SST anomalies over the key region occur at around day -6 and then amplify with the development and decay of the PNAs. The above results indicate the impacts of PNA on the intensification of those comparatively modest precursor SST anomalies over the key region, consistent with the results of Nigam (2003). To assess whether this is indeed the case, we calculated the anomalies of surface

(right) the negative PNA phase. For SST anomalies, contours start from $\pm 0.1 \mathrm{~K}$ with an interval of $0.1 \mathrm{~K}$ and zero lines are omitted. Red (blue) shadings indicate positive (negative) anomalies that are statistically significant at the $p<0.10$ level on a Monte Carlo test. The magenta rectangular box over the extratropical Pacific $\left(40^{\circ}-50^{\circ} \mathrm{N}, 160^{\circ}-200^{\circ} \mathrm{E}\right)$ denotes the key region, where SST anomalies are prescribed in the model study of Hurwitz et al. (2012). The magenta rectangular box over the tropical Pacific $\left(5^{\circ} \mathrm{S}-5^{\circ} \mathrm{N}, 120^{\circ}-170^{\circ} \mathrm{W}\right)$ denotes the Niño-3.4 region. For surface heat fluxes anomalies, contours start from $\pm 5 \mathrm{~W} \mathrm{~m}^{-2}$ with an interval of $10 \mathrm{~W} \mathrm{~m}^{-2}$ and zero lines are omitted. Surface heat fluxes anomalies displayed are statistically significant at the $p<0.10$ level based on a two-tailed Monte Carlo test. The amplitudes for WP and PNA are given at the bottom-left corner for each panel. 

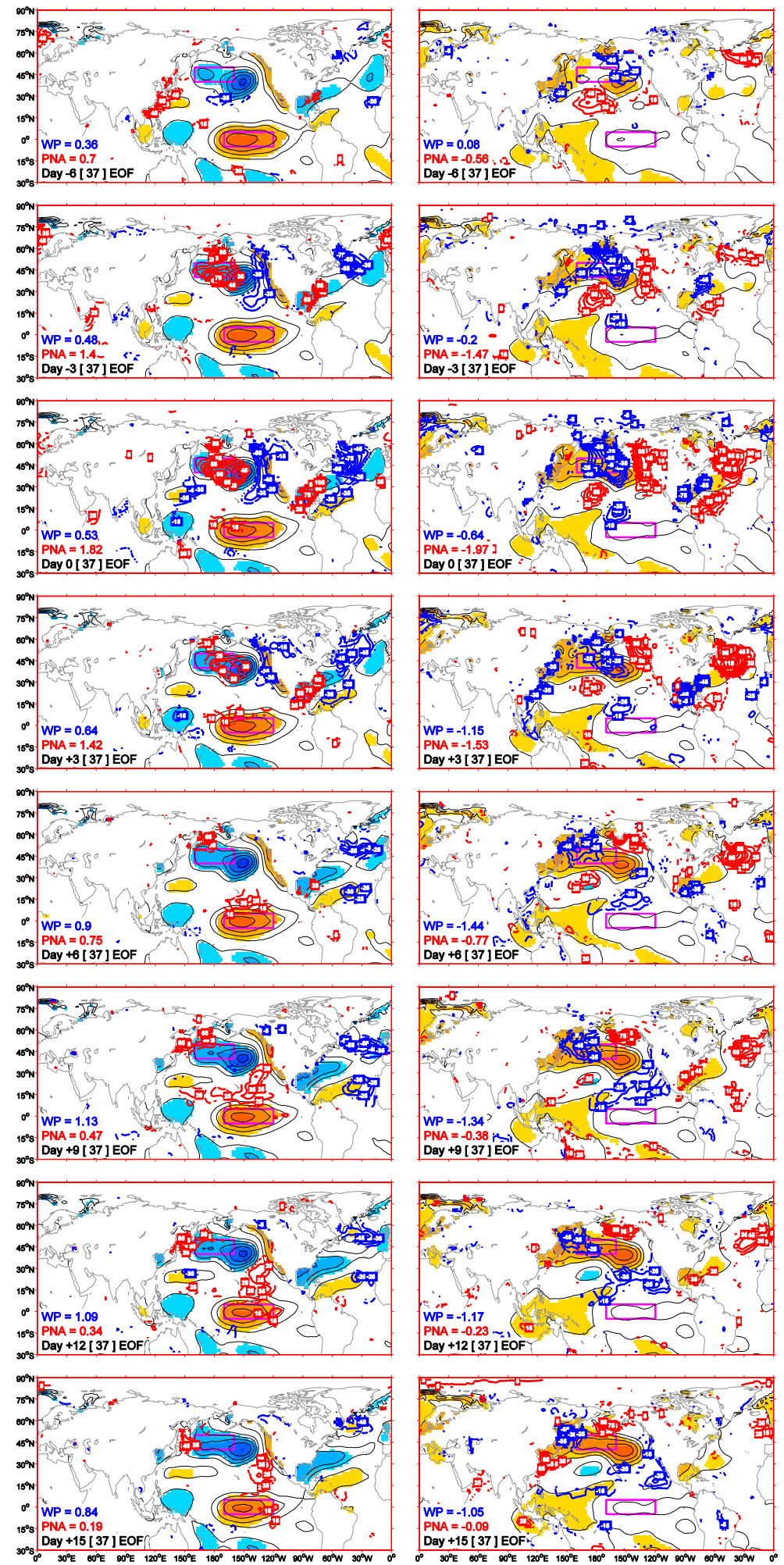

FIG. 11. As in Fig. 10, but for the PNA ${ }_{W}$ events. 
turbulent heat fluxes from the ocean to the atmosphere. For the positive $\mathrm{PNA}_{\mathrm{W}}$ composites (Fig. 11, left panels), from day -3 to day +3 , when the PNA index is beyond one standard deviation $\sigma$ and exceeds the amplitude of the WP index, statistically significant positive surface heat fluxes anomalies acts to drive the negative SST anomalies over the key region, consistent with the process revealed in Nigam (2003): first of all, anomalous surface westerlies of the mature phase positive PNA enhance the wind speed in midlatitudes by reinforcing the climatological westerlies (Fig. S7, left panels); then, increased wind speeds lead to greater surface heat fluxes (Fig. 11, left panels), and consequently, negative SST anomalies (Fig. 11, left panels). By contrast, from day +6 to day +15 , when the WP index is around $+1 \sigma$ and exceeds the amplitude of the PNA index, no significant surface heat flux anomalies can be observed over the key region (Fig. 11, left panels), indicating that the WP pattern plays little role in generating SST anomalies over the key region through modulating the surface heat fluxes. Consistently, for the negative PNA $_{\mathrm{W}}$ composites (Fig. 11, right panels), from day -3 to day +3 , when the PNA index is below $-1 \sigma$ and exceeds the amplitude of the WP index, anomalous surface easterlies diminish wind speed in midlatitudes by opposing the climatological westerlies (Fig. S7, right panels); then, decreased wind speeds lead to less surface heat fluxes (Fig. 11, right panels), and consequently, positive SST anomalies (Fig. 11, right panels). From day +6 on, when the WP index is below $-1 \sigma$ and exceeds the amplitude of the PNA index, the surface heat flux anomalies over the key region are weak and insignificant (Fig. 11, right panels), and thus have little effect on inducing SST anomalies. The above results suggest that the midlatitude SST anomalies over the key region in Fig. 11 are results of the preceding PNA, rather than of the development of WP. Because of the thermal inertia of the oceanic mixed layer, both intensity and persistence of the westerly/easterly forcing are crucial in determining the cumulative changes in SST. With these in mind, the difference between $\mathrm{PNA}_{\mathrm{W}}$ and $\mathrm{PNA}_{\mathrm{WO}}$ composites of SST anomalies over the key region can be understood. (Shown in Figs. S6-S7 are lagged composites of the daily surface wind anomalies based on the two different types and two phases of PNA events listed in the first column of Table S1.) It can be seen (Fig. S7) that, surface westerly anomalies associated with the positive $\mathrm{PNA}_{\mathrm{W}}$ events are significant and persistent over the key region (Fig. S7, left panels), and thus are sufficient to generate significant negative SST anomalies over the key region via enhancing surface heat fluxes (Fig. 11, left panels); which, in turn, might favor the occurrence of the succeeding positive WP events
(Fig. S5a, red curve), with the benefits of a previous modeling study by Hurwitz et al. (2012), where the causal relationship between SST anomalies over the key region and the WP pattern has been demonstrated, whereas no direct indication of the excitation mechanism has been shown in the modeling study. Consistently, surface easterly anomalies associated with the negative $\mathrm{PNA}_{\mathrm{W}}$ events are significant and persistent over the key region (Fig. S7, right panels), and thus are sufficient to generate significant positive SST anomalies over the key region via suppressing surface heat fluxes (Fig. 11, right panels); which, in turn, might favor the occurrence of the succeeding negative WP events (Fig. S5b, red curve). By contrast, the circulation anomalies of the $\mathrm{PNA}_{\mathrm{WO}}$ events are located equatorward of that of the $\mathrm{PNA}_{\mathrm{W}}$ events; as a result, surface wind anomalies over the key region are dominated by meridional components (Fig. S6), and thus are unfavorable for the accumulation of SST anomalies over the key region (Fig. 10). Instead, in this case, statistically significant SST anomalies are located equatorward of the key region, where there are significant surface heat flux anomalies (Fig. 10).

The above results highlight the potential role of the background westerlies and the extratropical air-sea interaction over the key region in the conversion from PNA into WP of the same polarity. It should be noted that the westward development of atmospheric systems have been discussed in many previous studies (e.g., Branstator 1987; Kushnir 1987; Lau and Nath 1999; Takaya and Nakamura 2005b), and have been attributed to some possible mechanisms, such as baroclinic development under the condition of weak thermal dissipation (Held et al. 1986) and hydrodynamic instability of the large-scale flow that could give rise to large-scale disturbances with periods longer than a week or two (Frederiksen 1983; Simmons et al. 1983).

The SST anomalies depicted in Fig. 11, over the Niño-3.4 region $\left(5^{\circ} \mathrm{S}-5^{\circ} \mathrm{N}, 120^{\circ}-170^{\circ} \mathrm{W}\right)$, provide further evidence for the impact of ENSO on the frequency of PNApreceded WP-I events, as revealed in Table 1 (second and fifth rows): the positive PNA-preceded WP-I events occur more often during WENSO winters ( 0.96 events per winter) than during CENSO winters (0.32 events per winter). Correspondingly, significantly positive SST anomalies in the Niño-3.4 region are observed (Fig. 11, left panels). Consistent with this, the negative PNA-preceded WP-I events occur more often in CENSO winters ( 0.64 events per winter) than in WENSO winters (0.39 events per winter), whereas in this case the biased distribution toward CENSO is comparatively modest. As a result, the negative SST anomalies in the Niño3.4 region are marginal and insignificant (Fig. 11, right panels). 
Acknowledgments. We thank three anonymous reviewers for their helpful comments, which improved the manuscript considerably. This research is supported by Chinese NSF Grants 41875065 and 41130962 . YD acknowledges support from the EU H2020 Blue-Action (GA 727852) project for this work. The authors thank NOAA/Earth System Research Laboratory/Physical Sciences Division for making available the NCEPNCAR reanalysis dataset and the Extended Reconstructed SST, version 4 (ERSST.v4), data.

\section{REFERENCES}

Athanasiadis, P. J., J. M. Wallace, and J. J. Wettstein, 2010: Patterns of wintertime jet stream variability and their relation to the storm tracks. J. Atmos. Sci., 67, 1361-1381, https://doi.org/ 10.1175/2009JAS3270.1.

Barnston, A. G., and R. E. Livezey, 1987: Classification, seasonality, and persistence of low-frequency atmospheric circulation patterns. Mon. Wea. Rev., 115, 1083-1126, https://doi.org/ 10.1175/1520-0493(1987)115<1083:CSAPOL >2.0.CO;2.

Baxter, S., and S. Nigam, 2013: A subseasonal teleconnection analysis: PNA development and its relationship to the NAO. J. Climate, 26, 6733-6741, https://doi.org/10.1175/ JCLI-D-12-00426.1.

Branstator, G., 1987: A striking example of the atmosphere's leading traveling pattern. J. Atmos. Sci., 44, 2310-2323, https:// doi.org/10.1175/1520-0469(1987)044<2310:ASEOTA > 2.0.CO;2.

Cash, B. A., and S. Lee, 2001: Observed nonmodal growth of the Pacific-North American teleconnection pattern. J. Climate, 14, 1017-1028, https://doi.org/10.1175/1520-0442(2001)014<1017: ONGOTP $>2.0 . \mathrm{CO} ; 2$.

Cheng, X., and T. J. Dunkerton, 1995: Orthogonal rotation of spatial patterns derived from singular value decomposition analysis. J. Climate, 8, 2631-2643, https://doi.org/10.1175/ 1520-0442(1995)008<2631:OROSPD > 2.0.CO;2.

Dai, Y., and B. Tan, 2016: The western Pacific pattern precursor of major stratospheric sudden warmings and the ENSO modulation. Environ. Res. Lett., 11, 124032, https://doi.org/10.1088/ 1748-9326/aa538a.

— S. B. Feldstein, B. Tan, and S. Lee, 2017: Formation mechanisms of the Pacific-North American teleconnection with and without its canonical tropical convection pattern. J. Climate, 30, 3139-3155, https://doi.org/10.1175/JCLI-D-16-0411.1.

Duchon, C. E., 1979: Lanczos filtering in one and two dimensions. J. Appl. Meteor., 18, 1016-1022, https://doi.org/10.1175/ 1520-0450(1979)018<1016:LFIOAT>2.0.CO;2.

Feldstein, S. B., 2000: The timescale, power spectra, and climate noise properties of teleconnection patterns. J. Climate, 13, 4430-4440, https://doi.org/10.1175/1520-0442(2000)013<4430: TTPSAC $>2.0 . \mathrm{CO} ; 2$.

- 2002: Fundamental mechanisms of the growth and decay of the PNA teleconnection pattern. Quart. J. Roy. Meteor. Soc., 128, 775-796, https://doi.org/10.1256/0035900021643683.

Franzke, C., and S. B. Feldstein, 2005: The continuum and dynamics of Northern Hemisphere teleconnection patterns. J. Atmos. Sci., 62, 3250-3267, https://doi.org/10.1175/ JAS3536.1.

, — , and S. Lee, 2011: Synoptic analysis of the Pacific-North American teleconnection pattern. Quart. J. Roy. Meteor. Soc., 137, 329-346, https://doi.org/10.1002/qj.768.
Frederiksen, J. S., 1983: A unified three-dimensional instability theory on the onset of blocking and cyclogenesis. II: Teleconnection patterns. J. Atmos. Sci., 40, 2593-2609, https://doi.org/10.1175/ 1520-0469(1983)040<2593:AUTDIT >2.0.CO;2.

Held, I. M., R. T. Pierrehumbert, and R. L. Panetta, 1986: Dissipative destabilization of external Rossby waves. J. Atmos. Sci., 43, 388-396, https://doi.org/10.1175/1520-0469(1986)043<0388: DDOERW $>2.0 . \mathrm{CO} ; 2$.

Horel, J. D., and J. M. Wallace, 1981: Planetary-scale atmospheric phenomena associated with the Southern Oscillation. Mon. Wea. Rev., 109, 813-829, https://doi.org/10.1175/1520-0493(1981) $109<0813$ :PSAPAW $>2.0$. CO 2 .

Huang, B., and Coauthors, 2015: Extended Reconstructed Sea Surface Temperature version 4 (ERSST. v4). Part I: Upgrades and intercomparisons. J. Climate, 28, 911-930, https://doi.org/ 10.1175/JCLI-D-14-00006.1.

Hurwitz, M. M., P. A. Newman, and C. I. Garfinkel, 2012: On the influence of North Pacific sea surface temperature on the Arctic winter climate. J. Geophys. Res., 117, D19110, https:// doi.org/10.1029/2012JB009463.

Johnson, N. C., and S. B. Feldstein, 2010: The continuum of North Pacific sea level pressure patterns: Intraseasonal, interannual, and interdecadal variability. J. Climate, 23, 851-867, https:// doi.org/10.1175/2009JCLI3099.1.

Kalnay, E., and Coauthors, 1996: The NCEP/NCAR 40-Year Reanalysis Project. Bull. Amer. Meteor. Soc., 77, 437-471, https:// doi.org/10.1175/1520-0477(1996)077<0437:TNYRP>2.0.CO;2.

Karoly, D. J., R. A. Plumb, and M. Ting, 1989: Examples of the horizontal propagation of quasi-stationary waves. J. Atmos. Sci., 46, 2802-2811, https://doi.org/10.1175/1520-0469(1989)046<2802: EOTHPO $>2.0 . \mathrm{CO} ; 2$.

Kodera, K., 1998: Consideration of the origin of the different midlatitude atmospheric responses among El Niño events. J. Meteor. Soc. Japan, 76, 347-361, https://doi.org/10.2151/jmsj1965.76.3_347.

Kosaka, Y., J. S. Chowdary, S. P. Xie, Y. M. Min, and J. Y. Lee, 2012: Limitations of seasonal predictability for summer climate over East Asia and the northwestern Pacific. J. Climate, 25, 7574-7589, https://doi.org/10.1175/JCLI-D-12-00009.1.

Kushnir, Y., 1987: Retrograding wintertime low-frequency disturbances over the North Pacific Ocean. J. Atmos. Sci., 44, 2727 2742, https://doi.org/10.1175/1520-0469(1987)044<2727:RWLFDO> 2.0.CO;2.

Lau, N. C., 1988: Variability of the observed midlatitude storm tracks in relation to low-frequency changes in the circulation pattern. J. Atmos. Sci., 45, 2718-2743, https://doi.org/10.1175/ 1520-0469(1988)045<2718:VOTOMS > 2.0.CO;2.

_ , and M. J. Nath, 1999: Observed and GCM-simulated westward-propagating, planetary-scale fluctuations with approximately three-week periods. Mon. Wea. Rev., 127, 2324-2345, https://doi.org/10.1175/1520-0493(1999)127<2324:OAGSWP > 2.0.CO;2.

Limpasuvan, V., D. L. Hartmann, D. W. J. Thompson, K. Jeev, and Y. L. Yung, 2005: Stratosphere-troposphere evolution during polar vortex intensification. J. Geophys. Res., 110, D24101, https:// doi.org/10.1029/2005JD006302.

Linkin, M., and S. Nigam, 2008: The North Pacific Oscillation-west Pacific teleconnection pattern: Mature-phase structure and winter impacts. J. Climate, 21, 1979-1997, https://doi.org/10.1175/ 2007JCLI2048.1.

Liu, W., and Coauthors, 2015: Extended Reconstructed Sea Surface Temperature version 4 (ERSST.v4). Part II: Parametric and structural uncertainty estimations. J. Climate, 28, 931-951, https://doi.org/10.1175/JCLI-D-14-00007.1. 
Liu, Y. Y., L. Wang, W. Zhou, and W. Chen, 2014: Three Eurasian teleconnection patterns: Spatial structures, temporal variability, and associated winter climate anomalies. Climate Dyn., 42, 2817-2839, https://doi.org/10.1007/s00382-014-2163-z.

Mori, M., and M. Watanabe, 2008: The growth and triggering mechanisms of the PNA: A MJO-PNA coherence. J. Meteor. Soc. Japan, 86, 213-236, https://doi.org/10.2151/jmsj.86.213.

Nakamura, H., M. Tanaka, and J. M. Wallace, 1987: Horizontal structure and energetics of Northern Hemisphere wintertime teleconnection patterns. J. Atmos. Sci., 44, 3377-3391, https:// doi.org/10.1175/1520-0469(1987)044<3377:HSAEON >2.0.CO;2.

Nigam, S., 2003: Teleconnections. Encyclopedia of Atmospheric Sciences, J. A. Curry and J. A. Pyle, Eds., Academic Press, 2243-2269.

Nishii, K., H. Nakamura, and Y. J. Orsolini, 2010: Cooling of the wintertime Arctic stratosphere induced by the western Pacific teleconnection pattern. Geophys. Res. Lett., 37, L13805, https://doi.org/10.1029/2010GL043551.

,-- , and — 2011: Geographical dependence observed in blocking high influence on the stratospheric variability through enhancement and suppression of upward planetary-wave propagation. J. Climate, 24, 6408-6423, https://doi.org/10.1175/ JCLI-D-10-05021.1.

Orsolini, Y. J., A. Y. Karpechko, and G. Nikulin, 2009: Variability of the Northern Hemisphere polar stratospheric cloud potential: The role of North Pacific disturbances. Quart. J. Roy. Meteor. Soc., 135, 1020-1029, https://doi.org/10.1002/qj.409.

Pak, G., Y.-H. Park, F. Vivier, Y.-O. Kwon, and K.-I. Chang, 2014: Regime-dependent nonstationary relationship between the East Asian winter monsoon and North Pacific Oscillation. J. Climate, 27, 8185-8204, https://doi.org/10.1175/JCLI-D-13-00500.1.

Plumb, R. A., 1985: On the three-dimensional propagation of stationary waves. J. Atmos. Sci., 42, 217-229, https://doi.org/10.1175/ 1520-0469(1985)042<0217:OTTDPO >2.0.CO;2.

Rivière, G., 2010: Role of Rossby wave breaking in the west Pacific teleconnection. Geophys. Res. Lett., 37, L11802, https://doi.org/ 10.1029/2010GL043309.

Rogers, J. C., 1981: The North Pacific Oscillation. J. Climatol., 1, 39-52, https://doi.org/10.1002/joc.3370010106.

_ 1990: Patterns of low-frequency monthly sea level pressure variability (1899-1986) and associated wave cyclone frequencies. J. Climate, 3, 1364-1379, https://doi.org/10.1175/1520-0442(1990) $003<1364:$ POLFMS $>2.0 . C O ; 2$.
Simmons, A. J., J. M. Wallace, and G. Branstator, 1983: Barotropic wave propagation and instability and atmospheric teleconnection patterns. J. Atmos. Sci., 40, 1363-1392, https://doi.org/ 10.1175/1520-0469(1983)040<1363:BWPAIA $>2.0$. CO 2 .

Takaya, K., and H. Nakamura, 2005a: Mechanisms of intraseasonal amplification of the cold Siberian high. J. Atmos. Sci., 62, 4423 4440, https://doi.org/10.1175/JAS3629.1.

, and - 2005b: Geographical dependence of upper-level blocking formation associated with intraseasonal amplification of the Siberian high. J. Atmos. Sci., 62, 4441-4449, https:// doi.org/10.1175/JAS3628.1.

— and _ 2013: Interannual variability of the East Asian winter monsoon and associated modulations of the planetary waves. J. Climate, 26, 9445-9461, https://doi.org/10.1175/ JCLI-D-12-00842.1.

Tanaka, S., K. Nishii, and H. Nakamura, 2016: Vertical structure and energetics of the western Pacific teleconnection pattern. J. Climate, 29, 6597-6616, https://doi.org/10.1175/ JCLI-D-15-0549.1.

Wallace, J. M., and D. S. Gutzler, 1981: Teleconnections in the geopotential height field during the Northern Hemisphere winter. Mon. Wea. Rev., 109, 784-812, https://doi.org/10.1175/ 1520-0493(1981)109<0784:TITGHF>2.0.CO;2.

Wang, L., and W. Chen, 2014: An intensity index for the East Asian winter monsoon. J. Climate, 27, 2361-2374, https://doi.org/ 10.1175/JCLI-D-13-00086.1.

Wettstein, J. J., and J. M. Wallace, 2010: Observed patterns of month-to-month storm-track variability and their relationship to the background flow. J. Atmos. Sci., 67, 1420-1437, https:// doi.org/10.1175/2009JAS3194.1.

Woollings, T., A. Charlton-Perez, S. Ineson, A. G. Marshall, and G. Masato, 2010: Associations between stratospheric variability and tropospheric blocking. J. Geophys. Res., 115, D06108, https:// doi.org/10.1029/2009JD012742.

Yu, J.-Y., and S. T. Kim, 2011: Relationships between extratropical sea level pressure variations and the central Pacific and eastern Pacific types of ENSO. J. Climate, 24, 708-720, https:// doi.org/10.1175/2010JCLI3688.1.

Yuan, J., B. Tan, S. B. Feldstein, and S. Lee, 2015: Wintertime North Pacific teleconnection patterns: Seasonal and interannual variability. J. Climate, 28, 8247-8263, https://doi.org/10.1175/ JCLI-D-14-00749.1. 